\title{
EVOLUCIÓN NORMATIVA DEL DERECHO DE LA MUJER A UNA VIDA LIBRE DE VIOLENCIA EN ECUADOR
}

\section{NORMATIVE EVOLUTION OF THE RIGHT OF WOMEN TO A LIFE FREE OF VIOLENCE IN ECUADOR}

\author{
Carmen Georgina Puchaicela Huaca ${ }^{1}$ \\ Ximena María Torres Sánchez ${ }^{2}$ \\ Universidad Técnica Particular de Loja.
}

\section{RESUMEN}

En la actualidad el Estado ecuatoriano ofrece un marco de reconocimiento amplio, respecto de la problemática de la violencia de género; por lo tanto, los mecanismos establecidos para la protección se articulan con distintos ejes; en el eje normativo, se presentan cambios sustanciales derivados del modelo constitucional vigente.

Con este antecedente, el presente estudio tiene 1 Carmen Georgina Puchaicela Huaca, cgpuchaicela@utpl.edu.ec , dirección Orcid: https://orcid. org/0000-0001-9947-9303

Investigadora Universidad Técnica Particular de Loja.

$2 \quad X i m e n a$ María Torres Sánchez, mail: xmtorres@ utpl.edu.ec , dirección Orcid: https://orcid.org/0000-00034867-7742

Investigadora Universidad Técnica Particular de Loja. el propósito de analizar la evolución normativa ecuatoriana, relacionada con el derecho a una vida libre de violencia. Para el efecto, se realiza un análisis hermenéutico desde la perspectiva histórica y descriptiva; desde donde se analiza lo estipulado en la norma fundamental $y$ secundaria, lo que conlleva implicaciones que repercuten en el establecimiento de políticas públicas e institucionalidad de amparo a las víctimas.

PALABRAS CLAVE: Derechos, humanas, fundamental, violencia, mujer.

\section{ABSTRACT}

Currently, the Ecuadorian State offers a wide 
recognition framework regarding the problem of gender violence, therefore, the established mechanisms for protection are articulated with different axes; in the normative axis, there are substantial changes derived from the current constitutional model.

With this background, the present study has the purpose of analyzing the Ecuadorian normative evolution, related to the right to a life free of violence. For this purpose, a hermeneutic analysis is carried out from the historical and descriptive perspective; from where it is analyzed, what is stipulated in the fundamental and secondary norm, which entails implications that affect the establishment of public policies and institutions for the protection of victims.

KEYWORDS: Rights, human, fundamental, violence, woman.

\section{INTRODUCCIÓN:}

El Estado Ecuatoriano se configura como un Estado de Derecho de acuerdo con el art. 1 de su norma constitucional; la instauración de este modelo, sehacaracterizadoporelestablecimiento de un sistema garante de principios y derechos fundamentales que se constituyen en la base esencial del desenvolvimiento estatal. En este contexto, se coloca a la Constitución como centro del accionar y norma suprema, en un ordenamiento que "conjuga los principales postulados del garantismo constitucional europeo, con respuestas propias e imaginativas a los retos políticos, sociales y culturales que se manifiestan en la región" (Montaña, 2012, p.39).

Así pues, el modelo de Estado de Derecho o Estado Constitucional instaurado, si bien podría ser en gran parte heredado del contexto europeo; en el espacio latinoamericano, adquiere nuevas connotaciones; mucho más en el ámbito ecuatoriano, en donde se introducen particularidades que propenden a insertar una respuesta eficaz a los problemas del contexto.
Los componentes adicionales que reporta el constitucionalismo latinoamericano refieren la incursión en el modelo de democracia participativa y constitucionalización de los derechos humanos en el derecho interno, fortalecimiento de la función judicial, incremento de los mecanismos garantes de derechos constitucionales y reconocimiento de la plurinacionalidad y multiculturalidad.

En este contexto, el derecho de las mujeres a una vida libre de violencia, se constituye en una de las normas que gozan de jerarquía constitucional, cuyas implicaciones jurídicas, conllevan consecuencias que, se articulan a una visión de protección preferente, lo que enlazado a determinados mecanismos pretenden el alcance de una mayor efectividad normativa.

\section{CONSTITUCIONALIZACIÓN DEL DERECHO A UNA VIDA LIBRE DE VIOLENCIA.}

En la actualidad en el Ecuador se establece un marco de respaldo ante las libertades e igualdades que cimientan los derechos humanos de las mujeres, lo que se traduce en la reconexión con aquel estado de bienestar, cuya consolidación tuvo lugar en Europa y EEUU, tendencia que en sus inicios incorporó en las constituciones aspectos referentes a derechos laborales dadas las exigencias en tiempos de la post industrialización, pero que más adelante se relacionaron con la integración de derechos y libertades en tiempos de post guerra.

Con la entrada en vigencia de la Constitución del año 2008 -que ha sido catalogada como garantista de derechos-, se incluye un amplio catálogo de derechos que constitucionaliza en la carta magna el derecho internacional de los derechos humanos, y que bajo la directriz del neoconstitucionalismo reconoce como fundamentales a los derechos básicos de las 
personas para su subsistencia, cuestión que como se advirtió con antelación es propio del modelo constitucional asumido.

Otro de los aspectos que derivan del modelo constitucional es la ampliación radical del sistema de garantías y la posibilidad de un mayor alcance de la exigibilidad de estos derechos fundamentales, la que se efectúa, mediante una doble dimensión individual y colectiva constitucionalmente se reconocen una serie de colectivos o grupos sociales-. De acuerdo a esta doble dimensión, la reivindicación individual de un derecho se hace extensible a la generalidad de los colectivos sociales y viceversa. (Ávila, 2009: 69)

Por lo tanto, el aspecto más relevante del modelo constitucional vigente, es la ampliación del sistema de garantías, en este sentido el Ecuador sitúa un marco amplio de mecanismos para hacer efectivo el alcance de derechos, así las garantías constitucionales engloban protección normativa, procesal, entre otros, lo que según Montaña (2012) denota diferencias entre el Estado constitucional, legal y social, en cuanto a que estos dos últimos "a pesar de tener un amplio catálogo de derechos, carecía de instrumentos que hagan posible su cumplimiento" (p.25).

Así la tutela de derechos constitucionales en el Ecuador abarca mecanismos de protección a nivel normativo, institucional, jurisdiccional y de políticas públicas. De manera muy general estas garantías refieren, la posibilidad del ejercicio del derecho; es decir que, el catálogo de derechos no se quede plasmado como meros enunciados, y tiendan a su respeto, ejercicio y protección.

El referirse al modelo constitucional vigente es importante, por cuanto al ser los derechos humanos de las mujeres internacionalmente reconocidos; y debido, al modelo constitucional actualmente vigente, se entiende una amplísima protección por el derecho de la mujer a una vida libre de violencia que ha sido efectivamente constitucionalizado. En este contexto, el derecho a una vida libre de violencia se encuentra establecido en el referido cuerpo legal, en el título segundo sobre los derechos, capítulo sexto, referente a los derechos de libertad, artículo 66 , numeral 3 , literal b, que contempla el derecho a la integridad personal que incluye "una vida libre de violencia en el ámbito público y privado..." (Constitución de la República del Ecuador, 2008).

De lo analizado previamente, resulta de suma importancia la incorporación de este derecho referente a la no violencia en la Carta Magna vigente en el Ecuador, dado que, desde la perspectiva del constitucionalismo, todos los derechos contenidos en la constitución adquieren la connotación de derechos fundamentales, cuya exigibilidad adquiere una doble dimensión individual y colectiva.

En tal virtud, este ente normativo se constituye en el eje principal, no solo para el respeto de derechos individuales y sociales, sino también para el ejercicio y la disposición de un trabajo interinstitucional mancomunado, respaldado desde varios niveles, con miras al cumplimiento y alcance de derechos básicos y necesarios para un nivel de vida adecuado para toda la población.

La definición de violencia es bastante amplia, según Cuesta (2014)

es en sí misma, una manifestación de la discriminación por sexo, que constituye una violación de derechos humanos, que persiste de manera generalizada y afecta a todos los países, y es la más perversa y reprobable manifestación de la discriminación contra la mujer. ( $p$. 170)

En tal virtud, el derecho a una vida libre de violencia dado el modelo constitucional 
vigente, goza de supremacía, no contradicción, inalterabilidad y de modo especial de la interdependencia, que atiende a la realización de derechos en atención al desarrollo integral de los seres humanos.

Desde la perspectiva de género, el derecho a una vida libre de violencia en el ámbito público y privado que refiere la norma constitucional, implica el reconocimiento del derecho de la mujer a un desarrollo integral, que repercute en la protección de derechos básicos de la mujer. Así la contemplación de este artículo se enlaza con el ejercicio de múltiples derechos humanos de la mujer en cuanto a desenvolverse sin temores en los distintos espacios de su vida, así por ejemplo incluye el hecho de que una mujer como cualquier ser humano, pueda circular libremente sin temor a ser agredida, a ser partícipe en igualdad de condiciones de las estructuras laborales, participar del ámbito público-social sin ser disminuida, desarrollarse en igualdad de condiciones y con autonomía en el ámbito privado.

Este avance normativo, resulta sobremanera importante, ya que trata de responder y considerar las necesidades sociales, y de modo específico, asume las carencias de la población femenina; por tal, trata de reparar situaciones tradicionales de falta de protección y lógicamente de desigualdad. En este sentido, se entiende la posibilidad de injerencia estatal en lo privado, aquel espacio que tradicionalmente y en la historia ha sido femenino; cuyos antecedentes, no referían intervención estatal, esto refleja según lo antes descrito, la constitucionalización de derechos humanos de la mujer, la inclusión de la perspectiva de género y en suma el empoderamiento de las mujeres para el ejercicio de sus propios derechos.

Es imperante la incorporación a nivel constitucional de este derecho, ya que la violencia no es de una sola clase, ni se limita a un contexto único, según Cuesta (2014) el ámbito de la violencia se amplía "a diferentes tipos de actos delictivos perpetrados directamente contra las mujeres por el simple hecho de serlo...que contribuye a la represión de las mujeres como personas y como grupo" (p. 167).

Más adelante el mismo artículo contempla que el Estado "adoptará las medidas necesarias para prevenir, eliminar y sancionar toda forma de violencia, en especial la ejercida contra las mujeres, niñas, niños y adolescentes...y contra de toda persona en situación de desventaja o vulnerabilidad", se establece una responsabilidad del Estado para combatir toda clase de violencia, así el ente estatal para cumplir con esta responsabilidad tiene potestad plena para implementar medidas con miras a frenar las referidas situaciones de violencia con atención especial a las mujeres y niñas.

Cuesta (2014) al respecto dice:

Esta violencia de género se inflige preponderantemente por hombres contra mujeres y niñas, y refleja $y$ refuerza las desigualdades entre hombres y mujeres y atenta contra la salud, la dignidad, la seguridad y la autonomía de las víctimas, influenciando el lugar que ocupan las mujeres en la sociedad (p. 167)

Se refleja entonces la necesidad de esta protección reforzada para la atención especial destinada a mujeres y niñas, de lo que podría inferirse diversos criterios, en cuanto a que estos grupos por un lado pudieren referir mayor situación de riesgo por ser colectivos vulnerables -atendiendo un tanto a criterios de vulnerabilidad que relacionan la situación biológica del individuo con las construcciones sociales predeterminadas-; o por cuanto debido a la realidad social históricamente patriarcal, estos grupos se han convertido en socialmente vulnerables. 
De este modo el Ecuador, de manera cuidadosa ha incorporado en la norma constitucional, aquellas connotaciones propias que emanan de los instrumentos internacionales específicos para la protección de la mujer contra la violencia, lo que incluye la garantía de incorporar mecanismos tendientes a subsanar estas vulneraciones, lo que se articula de manera armoniosa no solo con la realidad de la sociedad sino también con las necesidades del colectivo de mujeres.

Con la entrada en vigencia de la Constitución del año 2008, toda norma establecida en este cuerpo normativo refleja protección por una parte en cuanto a exigibilidad desde una doble dimensión; y, por otra parte, para el establecimiento de garantías constitucionales con miras al aseguramiento de los derechos desde múltiples ámbitos.

En cuanto a exigibilidad, a partir del año 2008, los derechos constitucionales dejan de ser subjetivos y adquieren la connotación de fundamentales, por lo que pueden ser exigibles desde una doble dimensión, individual y colectiva, de este modo existe una variación no sólo en cuanto a su ejercicio, sino además en cuanto a las posibilidades de reparación, cuyo beneficio se puede multiplicar colectivamente a todas las personas que son afectadas. En este sentido en atención a esta doble dimensión de los derechos

En esta misma línea para asegurar el cumplimiento de estos derechos se establecen garantías constitucionales que según Ávila (2009) "si se analiza desde el punto de vista de que los derechos de la constitución, no deben ser declaraciones que permanezcan en el papel y que deben materializarse" (p. 181), entonces tienen por fin establecer mecanismos para la protección de derechos desde diferentes ámbitos.
Así los derechos constitucionales, son el fin que se pretende alcanzar en materia de derechos y el sistema de garantías constitucionales se constituyen en los mecanismos o medios, para acercar el derecho a la realidad. Al referir el contexto ecuatoriano, distintos ámbitos de protección de derechos constitucionales, se comprende, la extensión de garantías normativas, institucionales, jurisdiccionales y de políticas públicas.

Por lo tanto, el derecho a la integridad personal que incluye una vida libre de violencia, refiere la garantía normativa de ser un derecho fundamental, goza de preferencia y supremacía frente a otros derechos. De acuerdo a esta garantía, cualquier contradicción normativa que pudiere presentarse al momento de resolverse una causa, no podrá ir en detrimento de estos derechos, con ello se asegura la prevalencia de derecho constitucional por sobre todas las normas secundarias existentes.

De igual modo se garantiza que los planes gubernamentales, políticas públicas, e instituciones públicas y privadas trabajen de modo articulado con miras a propender a un aporte en cuanto al alcance y cumplimiento de derechos básicos establecidos en la constitución. Asimismo, se garantiza que las normas o leyes que sean creadas favorezcan el alcance de la normativa constitucional.

Además, la violencia se deriva de la discriminación de la mujer en múltiples ámbitos de la sociedad, lo que establece estructuras que reproducen aquello que históricamente se ha evidenciado desde el feminismo, la desigualdad estructural. De ahí, la necesidad de trabajar no solo en la erradicación de este mal, sino también sobre la prevención y concienciación de la violencia de género.

En este sentido las principales instituciones públicas que trabajan con miras a la prevención y erradicación de la violencia en el contexto 
ecuatoriano son el Consejo Nacional para la Igualdad de Género y Ministerio de Justicia Derechos Humanos y Cultos respectivamente, estos entes planifican acciones encaminadas a la prevención de la discriminación y erradicación de la violencia respectivamente.

De manera general los Consejos Nacionales se crean con el fin de garantizar la igualdad y no discriminación de las personas, pueblos y nacionalidades y colectivos, a fin de fortalecer la unidad nacional en la diversidad y la construcción del Estado Plurinacional e Intercultural. (Ley Orgánica de los Consejos Nacionales para la Igualdad, 2014)

Entre los Consejos creados con este fin se encuentra el Consejo Nacional para la Igualdad de Género que, en este contexto, refiere la realización de acciones sobre formulación de políticas, información y estudios, tendientes a la prevención de la desigualdad y discriminación propiamente dicha.

Estos consejos pueden promover o fomentar medidas de acción afirmativa que para favorecer la igualdad entre los individuos y colectivos; $y$, erradicar costumbres 0 estereotipos discriminatorios, de ahí que su conformación incluye una conformación paritaria. Así el Consejo Nacional para la Igualdad asume estrategias de asesoría a instituciones del sector público, con miras a incorporar la perspectiva de género en los instrumentos de planificación nacional que el estado define. En este contexto la construcción participativa de la Agenda Nacional de Mujeres y la Igualdad de Género, es uno de los elementos que promueve una adecuada gestión intergubernamental.

Otro de los elementos de este organismo para la consecución de la prevención, alude a la implementación de herramientas metodológicas para hacer del principio de igualdad y no discriminación, una cuestión transversal para los proyectos de inversión pública, para el diseño de dichas herramientas se promueve la participación interinstitucional, tendiente a la planificación de acciones, en donde estos consejos cumplen una participación activa en consonancia con los fines de su creación.

El instrumento que orienta el accionar de este consejo es la Agenda Nacional de Mujeres y la Igualdad de Género, este documento ha sido trabajado con la participación de representantes de las mujeres y otros colectivos sociales del país, su aprobación se realizó después de diálogos políticos, consultas, encuentros, diálogos y talleres. La Agenda Nacional de Mujeres y la Igualdad de Género, se constituye en un elemento que reivindica a los sujetos de derecho, para ello plantea estrategias para cerrar las brechas de desigualdad.

Esta agenda propone nueve ejes que promueven el ejercicio de derechos y trasformaciones a nivel social, precisamente el eje número dos refiere una vida libre de violencia. Los lineamientos que se derivan de este eje, se enmarcan de manera general en el mejoramiento del acceso a la justicia y la transformación de patrones socioculturales para garantizar el derecho de las personas a una vida libre de violencia.

Otros lineamientos abordan puntos como el incremento en la cobertura del sistema de protección para víctimas de violencia, propender a la especialización del talento humano para la atención de víctimas de violencia, fortalecer la cobertura de Unidades Judiciales contra la violencia a la mujer y la familia, favorecer la generación de información, establecer mecanismos del delito de femicidio y facilitar la sensibilización de la sociedad frente a nuevos tipos penales.

Los avances de esta política, también integran la erradicación de la violencia de género con la Ley 103, sobre violencia contra la mujer y la familia y consiguiente creación de Comisarías de la Mujer y la Familia, que actualmente se han 
sustituido por las Unidades Judiciales contra la Violencia a la Mujer y la Familia. Otros aspectos importantes, se asientan en la incorporación de temas sobre la prohibición de la violencia en la Constitución del año 1998, la creación de nuevas instituciones estatales que se especializan en el tema específico de violencia, la aprobación del protocolo médico legal para peritajes, así como la incorporación de reglamentos y planes referente al tratamiento de víctimas de violencia.

Los avances se consolidan en la incorporación de los temas de violencia en la Constitución del año 2008 e incorporación del delito de femicidio en la normativa penal vigente. Otra de las instituciones estatales que trabajan en este ámbito como se había señalado anteriormente es el Ministerio de Derechos Humanos y Cultos; este ente de carácter público plantea entre sus objetivos incrementar la coordinación entre los actores del sector justicia, reducir el número de causas en las que se afecte las garantías al debido proceso, reducir los niveles de violencia en centros de atención al adulto y jóvenes, incrementar la reinserción de personas adulta y adolescentes en conflicto con la ley, incrementar la regulación en relación a los cultos, incrementar en número de proyectos de ley del sector justicia, mejorar la eficiencia operacional, el desarrollo del talento humano, uso eficiente del presupuesto e incrementar el cumplimiento de los derechos humanos a nivel nacional. (Tomado de la página oficial del Ministerio de Justicia y Derechos Humanos)

\section{NORMATIVA SECUNDARIA RELACIONADA A LA VIOLENCIA DE GÉNERO.}

En lo referente a la normativa secundaria ecuatoriana, a partir del año 1995, el ámbito de la violencia contra la mujer, era abordado mediante la Ley contra la violencia a la mujer y a la familia, denominada como ley 103. El fin de esta ley se encaminaba a "proteger la integridad física, psíquica y libertad sexual de la mujer y los miembros de su familia, mediante la prevención y sanción de la violencia intrafamiliar y los demás atentados contra sus derechos y los de su familia" (Ley 103, 1995, Art. 1).

Dicha ley, si bien refería la protección de la integridad psíquica, libertad sexual de la mujer y los miembros de la familia, establece además la clasificación de la violencia física, psicológica y sexual. Si bien es cierto la ley expresa concordancia con la normativa internacional y nacional referente a violencia; sin embargo, el ejercicio de derechos se torna complejo, dada la necesidad de reforzar la institucionalidad existente, de modo que el tratamiento de las víctimas sea el adecuado, se proceda con los trámites de manera ágil y principalmente la sanción responda al nivel de la afectación causada.

Como se ha revisado anteriormente con la entrada en vigencia de la Constitución de la República del Ecuador en el año 2008, que incluye el derecho constitucional de la mujer a una vida libre de violencia, se han referido avances normativos. En este contexto resulta necesaria la configuración de normas y procedimientos más específicos para el tratamiento de la violencia de la mujer, que, según lo establecido en la Carta Magna ecuatoriana, incluya procedimientos especiales y expeditos, pero mucho más allá incluya tratamiento especializado, protección y reparación integral.

Con este antecedente, la entrada en vigencia del Código Integral Penal COIP $^{3}$ en el año 2014, responde a la necesidad entre otras de la delimitación de tratamiento especializado y expedito, y ha favorecido a la incorporación de delitos que responden a la realidad de la sociedad actual.

En este sentido, el COIP aborda de manera especializada el tema de la violencia contra la 3 En adelante se hará referencia al Código Orgánico Integral Penal (2014), como COIP. 
mujer; en el libro primero sobre la infracción penal, título cuarto, sobre las infracciones en particular, capítulo segundo sobre los delitos contra los derechos de libertad, sección segunda delitos contra la integridad personal, parágrafo primero, titulado delitos de violencia contra la mujer o miembros del núcleo familiar, que inicia desde el artículo 155 al 159 y abarcan las formas de violencia que pueden presentarse, así como el tipo de sanción, que refiere delitos y contravenciones.

La incorporación del tema específico de violencia, implica un avance normativo importante, por cuanto permite abordar la problemática no sólo como contravención, sino también como delito. Además, en los artículos antes señalados, se delimita la figura de la violencia en cuanto a descripción y formas de sanción. Este avance normativo da fe de la respuesta del Derecho ante las necesidades concretas de las mujeres, mucho más al hablar de contextos intrafamiliares en donde el agresor puede ser no necesariamente el cónyuge sino otras personas más que se relacionan con el ámbito familiar.

El Código de Procedimiento Penal es la normativa que es reemplazada por el actual Código Orgánico Integral Penal, la mencionada ley no contenía de modo específico el tema de violencia contra la mujer, dado que se entendía que la normativa específica para el tratamiento de estos actos le corresponde a la Ley 103 antes descrita, de ahí que el Código de Procedimiento refería de manera muy escasa la violencia intrafamiliar.

Así la violencia intrafamiliar en el anterior Código de Procedimiento Penal se enunciaba de manera dispersa, y para señalar salvedades, así tenemos el caso de prohibición de caución, el señalamiento de la competencia de jueces especializados para conocer de temas de violencia que no incurran en delito, la imposibilidad de conversión del delito de acción pública a privada en los casos de violencia, no abstención del fiscal de iniciar la investigación penal.

De manera mucho más grave en el Código de Procedimiento Penal se señalaba una prohibición de denunciar descendientes contra ascendientes, o entre cónyuges salvo casos de lo considerado en las leyes de protección de la mujer y la familia, sin embargo al acudir a la referida Ley 103, pese a que la norma refiere que puede ejercer la acción cualquier persona agraviada, natural o jurídica que conozca de los hechos, sin embargo no contempla de modo expreso la prohibición o aprobación de este tipo de denuncias de descendientes contra ascendientes o incluso entre hermanos, cuestión que claramente podía resultar contradictoria.

Esto, de uno u otro modo, tendió a invisibilizar las situaciones de agresiones en contextos intrafamiliares, restarles gravedad e inclusive generar confusión ante la respuesta de la justicia frente a estos actos, dejando de lado incluso aquellas necesidades concretas de la víctima, que requiere por parte del derecho, el alcance de la justicia, protección y una reparación acorde al hecho del que fue víctima.

En el año 2014, se aprueba la normativa penal unificada denominada Código Orgánico Integral Penal COIP, que como su nombre lo indica integra la normativa penal sustantiva y adjetiva, con el fin de facilitar el tratamiento de delitos de una manera más ágil y efectiva. Así, la entrada en vigencia de esta normativa incluyó la tipificación de nuevos delitos y procedimientos, que aportan al óptimo desenvolvimiento de la administración de justicia.

Así el artículo 155 del Código Orgánico Integral Penal establece los parámetros de la violencia contra la mujer o miembros del núcleo familiar en los siguientes términos "se considera violencia toda acción que consista en maltrato físico, psicológico o sexual ejecutado por un miembro de la familiar en contra de la mujer o 
demás integrantes del núcleo familiar".

La delimitación de la violencia tanto por sus clases, como por el ámbito familiar -que corresponde a la esfera privada-, complementa plenamente la directriz que emana del derecho constitucional, así como la necesidad de regular la intervención del estado en la esfera privada. Esta claridad de la norma referida se debe a que el diseño del modelo constitucional vigente cuidó en detalle la delimitación de criterios en atención con los tratados y convenciones específicas de Derechos Humanos, de ahí que es lógico pensar que este diseño extrajo de estos instrumentos internacionales aquellas particularidades más importantes.

El mismo artículo 155 párrafo segundo contempla que la violencia puede darse por parte de un miembro de la familia en contra de uno o demás miembros del núcleo familiar -se entienden como miembros de este núcleo el cónyuge, la pareja en unión de hecho o en unión, ascendientes, descendiente, parientes hasta el segundo grado de afinidad, e inclusive la persona con quién se determine que se ha mantenido vínculos íntimos o afectivos. (Código Orgánico Integral Penal COIP, 2014, Art. 155)

La entrada en vigencia del Código Orgánico Integral Penal COIP refiere una respuesta clara, ágil y oportuna para estas necesidades sociales, de ahí que luego de la delimitación de los temas de violencia y las personas que podrían ejercerla en el ámbito intrafamiliar, la norma pasa a describir el ámbito las formas en las que puede ejercerse violencia a la cual califica como delito o contravención dependiendo de sus características.

Es importante hacer un paréntesis para señalar que el Código Orgánico Integral Penal viene a reemplazar al Código penal, Código de Procedimiento Penal y de algún modo llega a suplir la Ley contra la violencia a la mujer y la familia o ley 103.
De modo general cabe mencionar los avances puntuales que trae consigo la incorporación del Código Orgánico Integral Penal COIP como reemplazo o complementación de las leyes referidas, así primeramente es importante indicar que el Código de Procedimiento Penal no incluía la variedad de posibles agresores que ampliamente describe la norma vigente al respecto. De ahí se deduce que de este modo se amplía la posibilidad de protección a las personas susceptibles de sufrir estas agresiones, ya que por ejemplo en la actualidad la norma inclusive refiere la existencia de un vínculo íntimo o afectivo.

Otra anotación importante es que en las normas que anteceden al COIP, no se establecía de manera concreta el delito de violencia en el contexto del ámbito familiar, y en el caso de la Ley 103 que sí refería este tema sin embargo al tratar los temas de violencia a nivel de contravención, la protección no se articulaba con un carácter de integralidad. Al atenerse, en el caso de la Ley contra la violencia a la mujer y la familia, a la sanción con amonestaciones económicas, restitución de bienes y en el caso de no disponibilidad de fondos al trabajo comunitario, la sanción para la acción de violencia ejercida por parte del sujeto no equivale a un resarcimiento de los actos en donde la persona que agreda pueda efectivamente rehabilitarse y no volver a cometer el acto. Esto va de la mano de la necesidad de una debida reparación integral y además de la necesidad de un tratamiento adecuado de las víctimas por parte de los funcionarios de los organismos estatales que se involucran en el proceso de recabar las evidencias sobre los hechos.

Una vez puntualizados, de forma sintética, los avances normativos y retomando el análisis del Código Orgánico Integral Penal COIP es importante señalar que la delimitación de los tipos de violencia se encuentra claramente enunciados. Así pues, el art. 156 del Código 
Orgánico Integral Penal COIP, contempla la violencia física como un delito, en tal virtud tipifica que "La persona que, como manifestación de violencia contra la mujer o miembros del núcleo familiar, cause lesiones, será sancionada con las mimas penas previstas para el delito de lesiones aumentada en un tercio".

Se deduce del artículo que antecede la norma constata que la violencia causa un daño real en la víctima, y que dada la afectación que sufra debe imponerse como sanción la pena privativa de libertad para el agresor. En tal virtud el delito sanciona con base a los mismos parámetros que el delito de lesión aumentada en un tercio.

Para la imposición de la sanción el artículo 152 del Código Orgánico Integral Penal que refiere el delito de lesiones establece una especie de parámetros para la sanción con pena privativa de libertad. Así depende del tiempo de lesión producida y tiempo de incapacidad provocado en la víctima, para que la sanción con pena privativa de libertad sea entre cuatro días en los casos menos graves - de incapacidad de cuatro a ocho días-, y un máximo de siete años en los actos que derivan mayor gravidez - cuando la incapacidad produce pérdida de sentido, del habla, incapacidad permanente, pérdida de algún órgano o enfermedades incurables-.

Este cambio para el tratamiento de violencia física en la normativa vigente es importante, en cuanto trata de aplicar la pena en función del daño producido, además de que el hecho de privación de libertad para el agresor implica no solo el castigo y oportunidad de resarcimiento, sino además se convierte en una forma de distanciar a la víctima del agresor y con ello protegerla.

El artículo 157 del Código Orgánico Integral Penal sobre la violencia psicológica contempla: "La persona que, como manifestación de violencia contra la mujer o miembros del núcleo familiar, cause perjuicio en la salud mental por actos de perturbación, amenaza, manipulación, chantaje, humillación, aislamiento vigilancia, hostigamiento o control de creencias, decisiones o acciones...". En este caso la sanción se establece con bases a criterios de daño leve, afectación de manera moderadas daño y psicológico severo.

Esta sanción que se da en función del perjuicio en la salud mental de la víctima, como producto de los actos antes detallados, en el caso de daño leve que incluye afectación del funcionamiento integral de las personas en los ámbitos somáticos de comportamiento y de relaciones, la pena fluctúa entre treinta a sesenta días de pena privativa de la libertad.

Cuando los daños producen afectación moderada en cualquiera de las áreas de desenvolvimiento personal, laboral, escolar, familiar o social de la víctima, llegando a la afectación de su desempeño cotidiano y requiriendo de tratamiento especializado, el agresor será sancionado con pena privativa de libertad de seis meses a un año. En el caso de que el daño psicológico en la víctima, provoque una afectación más severa que aún con intervención especializada no se pueda revertir; la pena que se establece es de uno a tres años.

Sin lugar a dudas la tipificación del delito de violencia psicológica, aporta de manera importante a la protección de la mujer que sufre violencia, de modo especial en el contexto intrafamiliar, en donde según la normativa previa, no disponía de medios para garantizar su protección, e inclusive la violencia de este tipo tendía e a ser invisible inclusive para la propia víctima.

Un factor clave para la protección de las víctimas de este tipo de violencia, en cuanto a propender a la reparación integral, es la incorporación de acompañamiento de carácter especializado, de ahí que mejora la atención y acompañamiento especializado por parte de un profesional, dado 
que según estudios sobre la violencia desde un punto de vista psicológico, su desenvolvimiento no es estático y de agresión constante, sino se presenta en ciclos, en donde la persona afectada puede atravesar momentos de explosión de la violencia, hasta momentos de amor profundo. (Gil, 2007:.46)

En cuanto a la violencia sexual, el artículo 158 refiere "la persona que, como manifestación de violencia contra la mujer o un miembro del núcleo familiar, se imponga a otra y la obligue a tener relaciones sexuales, $u$ otras prácticas análogas, será sancionada con las penas previstas en los delitos contra la integridad sexual y reproductiva". Se verifica que la expresión de la violencia mediante la coacción de imponerse y obligar a otra persona a tener relaciones sexuales o prácticas análogas, se reconoce en el Código Orgánico Integral Penal COIP, como un delito.

Para el efecto de la sanción la norma remite a las penas previstas en los delitos contra la integridad sexual y reproductiva de la misma normativa. En el referido apartado se establecen delitos como inseminación no consentida, privación forzada de capacidad de reproducción, acoso sexual, estupro, distribución de material pornográfico, corrupción de niños, abuso sexual, violación, utilización de personas para exhibición pública con fines sexuales, contacto con menores por medio electrónicos con fines sexuales, oferta de servicios sexuales con menores.

En este sentido el delito de violencia sexual se articula de manera indirecta con el abuso sexual y con la violación. En cuanto al abuso sexual el artículo 170 del Código Orgánico Integral Penal refiere que "la persona que, en contra de la voluntad de otra, ejecute sobre ella u obligue a ejecutar sobre sí misma o sobre otra persona, un acto de connotación sexual, sin que exista penetración o acceso carnal".
Se establece según la norma una especie de condición negativa que configura el abuso sexual en cuanto a que no existe la penetración, configurado el delito la sanción que se contempla para estos actos es de pena privativa de libertad de tres a cinco años. Esta sanción se establece para el caso de que el acto se comete sobre personas mayores de edad.

En el caso de menores de catorce años o que poseen algún tipo de discapacidad la sanción que se establece es de cinco a siete años y en el caso de que el hecho se ejecute sobre menores de seis años la pena privativa de libertad es de siete a diez años.

Cabe hacer un paréntesis, para analizar lo establecido en la norma en cuanto al delito de abuso sexual; ya que, con tal estipulación, de ser denunciado el acto ante las autoridades competentes, resulta complejo de ser probado. Esto, por cuanto la normativa, requiere para la configuración del delito, la coacción de la voluntad de la persona, así como el hecho de no experimentar acceso carnal -lo que constituye prueba del acto-.

Por otra parte, según la configuración descrita para el delito de abuso sexual, se hace mención sobre la voluntad, la capacidad de comprender el significado del hecho; es decir, no poderse resistir. Nuevamente y dado el caso de ser investigada una denuncia sobre este tipo de acto, la sospecha recaería nuevamente sobre la víctima, en cuanto a saber, si el acto fue contra su voluntad, o si efectivamente, ha podido resistirse.

Desde los análisis del feminismo jurídico ya se había denunciado estos temas, en cuanto a que; se tiende a investigar el hecho, desde el comportamiento de la víctima, se cuestiona su voluntad, se necesita saber si pudo o no resistirse al acto; dado el caso de juicio, estos cuestionamientos, consistirían en la exposición de la víctima. En este sentido, se distrae la 
atención, del fondo de los actos que vulneran derechos de un ser humano, restando incluso importancia al significado del acto en sí mismo; finalmente, se distrae la atención, de la cuestión esencial, que es el delito que ha cometiendo el agresor.

El artículo 171 del Código de Procedimiento Penal respecto de la violación contempla que es violación "el acceso carnal, con introducción total o parcial del miembro viril, por vía oral, anal o vaginal; o la introducción, por vía vaginal o anal, de objetos, dedos $u$ órganos distintos al miembro viril, a una persona de cualquier sexo".

Se configura este delito con el acceso del miembro viril, dedos u objetos. La sanción que se establece para este delito es de pena privativa de la libertad de diecinueve a veintidós años, cuando exista privación de la razón de la víctima, discapacidad, uso de violencia, amenaza o intimidación o cuanto la víctima sea menor de edad.

Cabe hacer un paréntesis, para analizar el delito de violación, entendido como violencia en los contextos intrafamiliares; del análisis de la normativa que antecede, se infiere la necesidad de normas que refieran particularidades adicionales en el caso de la violación. Es decir, con esta delimitación de la norma, la violación conyugal difícilmente llegará a las instancias judiciales, este tema ha sido ampliamente abordado por el feminismo jurídico, desde donde se ha expuesto que, este tipo de delitos, requieren para su judicialización, de circunstancias adicionales, que no conlleven a cuestionar la voluntad de la víctima, o su derecho a expresar la negativa de tener relaciones sexuales conyugales; mucho más aún, tratar de anteponerse un vínculo matrimonial, o de hecho, entre la víctima y el agresor.

La norma así planteada, devuelve la atención nuevamente sobre el consentimiento de la mujer, más no en lo que significa para el agresor imponerse, para ejercer una relación de poder manifiesta sobre su pareja. La herencia discriminatoria, propia de la cultura patriarcal conlleva inclusive a que, la mujer difícilmente reconozca que es víctima de violación por parte de pareja, o que es violentada, cuando es obligada sexualmente a hacer algo de lo cual no disfruta o que no quiere hacer.

En tal virtud se corre el riesgo de que estos delitos, que podrían estarse produciendo en la esfera privada queden impunes, y en el supuesto caso, de ser judicializados, constatada la existencia de vinculo y cuestionada la voluntad para acceder, quedaría la decisión a criterio del juzgador, que con base a derecho y a las pruebas aportadas deberá resolver; en este último caso para la decisión influirían las creencias personales, las posturas filosóficas y la intención del juzgador por incluir la perspectiva de género, para obtener un fallo favorable dado el caso.

Retomando el análisis del ámbito de violencia contra la mujer en el Código Orgánico Integral Penal, se establece una contravención para el tratamiento de violencia, al respecto el artículo 159 contempla: "la persona que hiera, lesione o golpee a la mujer o miembros del núcleo familiar, causándole lesiones o incapacidad que no pase de tres días"

En el caso de esta contravención de violencia contra la mujer o miembros del núcleo familiar delimita la contravención en la causa de lesiones en la persona agredida o incapacidad no mayor a tres días, para esta contravención el artículo 159 del Código Orgánico Integral Penal establece una sanción de privación de libertad de siete a treinta días.

Es importante el señalamiento de esta contravención en la norma, la que ha sido delimitada correctamente, en cuanto a los menores daños producidos, sin embargo, la sanción debería implicar conllevar a la asignación 
de la pena máxima, lo que pretende producir en el agresor ánimos de cambio y criterios de no reincidencia.

De manera general la tipificación de la violencia contra la mujer en el Código Orgánico Integral Penal COIP, Es destacable en cuanto a que refleja mayor preocupación por establecer sanciones apropiadas y delimitaciones para los delitos.

Es rescatable mencionar que, al elevar la violencia a la categoría de delito, refleja avances importantes respecto de la Ley 103 , que, aunque incluía clasificación sobre formas de violencia, trámites, medidas sin embargo la sanción no implicaba privación de libertad, lo que podría derivar fácilmente en reincidencia.

A continuación, para concluir con el análisis del Código Orgánico Integral Penal en el marco de defensa del derecho de la mujer a una vida libre de violencia, es importante revisar la incorporación del delito de femicidio como la sanción final en que pueden derivar las situaciones de violencia contra la mujer que incluyen la muerte de la persona.

La existencia de vínculos afectivos entre víctima y agresor, refieren un cúmulo de circunstancias que conllevan mayor carga emocional, en los actos de agresión que se cometen, de ahí que existe una estrecha línea entre la violencia física, sexual y la provocación de la muerte. En este contexto la vigencia del Código Integral Penal trajo consigo la inclusión de nuevos tipos penales, entre los que se encuentra además el delito de femicidio; esta inclusión es producto de investigaciones institucionales emprendidas por parte del Consejo Nacional para la Igualdad de Género, estudio sobre los fallos judiciales, publicaciones en medios e incidencia de grupos de mujeres.

De ahí que el Código Orgánico Integral Penal en el capítulo segundo sobre los delitos contra los derechos de libertad, sección primera sobre la inviolabilidad de la vida artículo 141 tipifica al femicidio como:

La persona que, como resultado de relaciones de poder manifestadas en cualquier tipo de violencia, dé muerte a una mujer por el hecho de serlo o por su condición de género, será sancionada con pena privativa de libertad de veintidós a veintiséis años. (Código Orgánico Integral Penal, 2014)

Es importante resaltar que, el delito de femicidio antes citado, denota la inclusión de la perspectiva de género en esta normativa, dado que el tipo penal descrito refiere la existencia de una relación de poder, es decir la imposición de la voluntad de forma manifiesta, en donde un individuo pretende someter a otro y afirmar su estatus de dominio. El referido artículo 141 menciona además la muerte de la mujer por el hecho de serlo o por su condición de género, esto implica la protección de manera directa de la vida e integridad personal de las mujeres.

Entre las circunstancias que se establecen como agravantes del femicidio, y que serían motivo de imposición de la pena máxima de veintiséis años están: el establecimiento o intención de establecer una relación de pareja, la existencia de una relación de tipo familiar, laboral, sentimental, escolar o que implique confianza o subordinación, el cometimiento del acto en presencia de hijos o familiares y la exposición del cuerpo en un lugar público.

Así la inclusión del femicidio retoma la trascendencia de la normativa internacional ratificada por el Ecuador, recoge el mandato de las normas constitucionales previstas para la protección de la mujer, que denotan además la preocupación social generalizada y liderada por los grupos de mujeres, en cuanto a la alarmante necesidad de colocar a la mujer como el bien jurídico de tutela y protección. 
En esta figura delictiva se distinguen claramente los componentes del sujeto activo, sujeto pasivo, acción, bien jurídico, elementos normativos. En cuanto al sujeto pasivo de acuerdo a lo previsto en el Código Orgánico Integral Penal, es el titular del bien jurídico que se protege, en este caso el sujeto pasivo es la mujer.

Sobre la acción de este tipo penal que constituye el verbo rector es matar, este sería el núcleo de este tipo penal. En cuanto al bien jurídico que se protege en el delito de femicidio es la vida de la mujer Finalmente sobre los elementos normativos que se articulan con las normas internacionales sobre este tema y se afirma en patrones culturales, tenemos la relación de poder, condición de mujer y la condición de género.

Una cuestión importante de señalar es que según lo establecido en el artículo 141 del Código Orgánico Integral Penal, el sujeto activo puede ser cualquier persona y el sujeto pasivo siempre es una mujer, por tal motivo se infiere que el sujeto activo puede ser hombre o mujer, no es necesariamente un hombre.

El femicidio refiere categorías que se han establecido en íntimo, no íntimo y por conexión. Según Yépez (2014) "cabe precisar que las categorías del femicidio se diferencia de este modo: la primera se refiere a los asesinatos cometidos por hombre con quien la víctima tenía o tuvo una relación íntima, familiar, de convivencia o afines a estas, la segunda agrupa a los cometidos por hombres con quienes la víctima no tenía relaciones íntimas familiares de convivencia o afines a éstas, constatándose que frecuentemente, el femicidio no íntimo involucra el ataque sexual de la víctima; la tercer categoría constituye los femicidios por conexión, en los que las víctimas son las mujeres que fueron asesinadas en la línea de fuego de un hombre tratando de matar a una mujer"
Las categorías del femicidio antes mencionadas, aunque son de trascendencia para lograr mayor claridad normativa, las mismas no han sido contempladas en el Código Integral Penal por cuanto esta sería una falencia a la hora de aplicar la norma y sobre todo lograr su eficacia. Por otra parte, dado que el femicidio involucra circunstancias de tiempo y espacio, y graves daños producidos en las mujeres por conocidos $y$ desconocidos resulta necesaria la incorporación de las categorías propias de este tipo penal.

Sería entonces la inclusión del delito de femicidio, la respuesta para un problema de la realidad social ecuatoriana y que en tal virtud adquiere grandes dimensiones. Otra anotación en cuanto a las necesidades que debió atender el Código Orgánico Integral Penal con miras a combatir la violencia contra las mujeres, la señala la Agenda Nacional de Mujeres para la Igualdad de Género (2014-2017), según la cual

La acción u omisión que implique daño, pérdida, transformación, sustracción, destrucción, retención o distracción de objetos, instrumentos de trabajo, documentos personales, bienes, valores, derechos o recursos económicos destinados a satisfacer las necesidades de algunas de las personas mencionadas en la definición de la violencia doméstica. (p. 75)

En conclusión, todos los avances normativos e incorporación de figuras delictivas, implican sin lugar a dudas el combate de la violencia como producto de estructuras sociales desiguales, discriminaciones reiteradas y existencia de relaciones de poder que colocan a la mujer en un estado de desventaja.

Aunque la normativa ha reflejado un reconocimiento tardío de esta necesidad de la sociedad, los avances son ya trascendentales, en cuanto a la protección de la mujer, de tal suerte que se pueda proteger su vida y salvaguardar 
derechos. Finalmente, todo contribuye a la consolidación de la promoción, ejercicio, garantía y defensa del derecho humano de la mujer a una vida libre de violencia.

\section{EXPEDICIÓN DE LA LEY ORGÁNICA INTEGRAL PARA PREVENIR Y ERRADICAR LA VIOLENCIA CONTRA LAS MUJERES}

El 5 de febrero de 2018, vislumbra un futuro prometedor en cuanto a la evolución normativa, para el tratamiento de la violencia contra la mujer en el Ecuador, con la expedición de una norma específica, para la prevención y erradicación de la violencia contra las mujeres. De esta manera, la norma, incluye aspectos importantes relacionados con, la obligación ineludible del Estado, frente a la garantía del derecho humano a una vida libre de violencia (Ley Orgánica para erradicar y prevenir la violencia contra las mujeres, 2018, Art. 5), categoriza los tipos de violencia en física, psicológica, sexual, económica, simbólica, política y ginecológica violencia (Ley Orgánica para erradicar y prevenir la violencia contra las mujeres, 2018, Art. 10), tipifica un sistema nacional integral para prevenir y erradicar la violencia contra las mujeres con ejes de prevención, atención, protección, reparación violencia (Ley Orgánica para erradicar y prevenir la violencia contra las mujeres,, 2018, Art. 13-66).

Con este antecedente, dado que la expedición de la Ley Orgánica Integral para prevenir, sancionar y erradicar la violencia contra las mujeres es reciente, es posible predecir un mejoramiento al tratamiento específico de este problema social; sin embargo, aún no es posible determinar posibles puntos a favor o en contra de esta norma, puesto que habrá que evaluarla tras un tiempo de su aplicación.

Sin embargo, no se puede dejar de reconocer la importancia de la expedición de esta norma específica, para el avance y evolución normativa, con miras al mejoramiento y vigencia de los derechos de las mujeres en el Ecuador.

\section{CONCLUSIONES:}

- La constitucionalización de los derechos humanos, entre ellos el Derecho a una vida de violencia, conlleva importantes avances que se articulan de manera directa con los mecanismos de garantías que apuntan a la mayor efectividad de los derechos.

- Se constata una importante evolución sobre el reconocimiento de derechos humanos de las mujeres, tomando como punto de partida, el derecho a una vida libre de violencia.

- Se identifica una falta de mayor especificación de normas; principalmente, políticas públicas, que permitan una verdadera consolidación de la normativa existente.

- A manera de hipótesis, es posible inferir la necesidad de trabajar los temas sobre género, en la formación de abogados con miras a un alcance futuro, de esta perspectiva como un argumento central, no solo en lo normativo, sino, además, en lo práctico y operativo.

- El estudio cumple con el objetivo de constatar la evolución y avance normativo, sin embargo, resulta necesario el contraste del marco jurídico con la aplicación de criterios judiciales, mediante el análisis de sentencias o casos, lo que será motivo de una próxima investigación. 


\section{REFERENCIAS BIBLIOGRÁFICAS}

Ávila, R., (2009). Los derechos y sus garantías ensayos críticos. Pensamiento Jurídico Contemporáneo N. 1. Corte Constitucional para el período de transición. Quito: Centro de Estudios y Difusión del Derecho Constitucional.

Benavides, J., Escudero, J. (coords.), (2013). Manual de justicia cosntitucional ecuatoriana. Quito, Cuadernos de Trabajo N. 4. Corte Constitucional. Quito: Centro de Estudios y Difusión del Derecho Constitucional.

Bobbio, N., (1991). El tiempo de los Derechos. Madrid: Editorial Sistema.

Boletín del Instituto Nacional de Estadísticas y Censos. (2012). Recuperado de: http://www. ecuadorencifras.gob.ec/ violencia-de-genero/

Caicedo \& Porras (eds.). (2010). Igualdad y no discriminación. El reto de la diversidad. Quito: V\&M Gráficas.

Código de Procedimiento Penal (2000). Recuperado de: http://www.oas.org/ juridico/mla/sp/ecu/sp_ecu-int-textcpp-ro360s.html

Código Orgánico Integral Penal (2014). Ecuador: Asamblea Nacional del Ecuador.

Constitución de la República del Ecuador (2008). Recuperado de: http:// www.asambleanacional.gob.ec/ es/leyes-aprobadas

Convención Interamericana para prevenir, sancionar y erradicar la violencia contra la mujer Convención de Belém do Pará ". Recuperado de: http://www.cidh.org/ Basicos/Basicos8.htm
Convención sobre la eliminación de todas las formas de discriminación contra la mujer CEDAW. Recuperado de: http://www. un.org/womenwatch/daw/cedaw/text/ sconvention.htm

Cuesta \& Santana (directores). (2014). Estado de Derecho y discriminación por razón de género, orientación e identidad sexual. España: Editorial Aranzadi, SA.

Gil, F. (2007). La violencia de género. Barcelona: Editorial UOC.

Instituto Nacional de Estadisticas y Censos. Encuesta Nacional sobre Relaciones Familiares y Violencia de Género contra las Mujeres (2011). Recuperado de: http://www.ecuadorencifras. gob.ec/violencia-de-genero/

Ley contra la violencia a la mujer y la familia, Ley 103 (1995). Ecuador. Recuperado de: pdba.georgetown.edu/Security/ citizensecurity/ecuador/leyes/ leyviolenciamujer.pdf

Ley orgánica de los consejos nacionales para la igualdad. Recuperado de: http://www. igualdadgenero.gob.ec/

Ley Orgánica Integral para Prevenir y Erradicar la Violencia contra las mujeres. (2018). Recuperado de: https://www. asambleanacional.gob.ec/sites/ default/files/private/asambleanacional/ filesasambleanacionalnameuid-29/ Leyes\%202013-2017/361-erradviolencia-contra-mujeres-18-08-2017/ ro-contra-violencia-mujer.pdf

MacKinnon, C. (1983). Feminism, Marxism, Method, and the State: toward Feminist Jurisprudence. Sings, Vol. 8. No. 4, pp. 635-658. Recuperado de: http://www. 
jstor.org/stable/3173687

Maquieira, V. (ed.) (2010). Mujeres, globalización y derechos humanos. Madrid: Cátedra.

Montaña, J., Porras, A. (eds.) (2012). Apuntes de Derecho Procesal Constitucional. Cuadernos de Trabajo Tomo 2. Corte Constitucional para el período de transición. Quito: Centro de Estudios y Difusión del Derecho Constitucional.

Plan Nacional del Buen Vivir 20132017. Ecuador, Senplades. Recuperado de: http://www. buenvivir.gob.ec/

Plan Nacional de Desarrollo para toda una vida 2017-2021. Ecuador, Senplades. Recuperado de: http://www. planificacion.gob.ec/wp-content/ uploads/downloads/2017/10/PNBV26-OCT-FINAL_OK.compressed1.pdf

Plan Nacional de Erradicación de la Violencia de Género hacia niñez, adolescencia y mujeres (2007). Ecuador. Recuperado de: http://erradicacionviolenciagenero. blogspot.com/

Yépez, M. (2014). El Femicidio en el C.O.I.P. Recuperado de: http:// www.derechoecuador.com / articulos/detalle/archive/doctrinas/ derechopenal/2014/03/27/elfemicidio-en-el-coip 